\title{
Development and optimization of the Suna trap as a tool for mosquito monitoring and control
}

\author{
Alexandra Hiscox ${ }^{1 *}$, Bruno Otieno ${ }^{2}$, Anthony Kibet ${ }^{2}$, Collins K Mweresa ${ }^{2}$, Philemon Omusula ${ }^{2}$, Martin Geier ${ }^{3}$, \\ Andreas Rose ${ }^{3}$, Wolfgang R Mukabana ${ }^{2,4}$ and Willem Takken ${ }^{1}$
}

\begin{abstract}
Background: Monitoring of malaria vector populations provides information about disease transmission risk, as well as measures of the effectiveness of vector control. The Suna trap is introduced and evaluated with regard to its potential as a new, standardized, odour-baited tool for mosquito monitoring and control.

Methods: Dual-choice experiments with female Anopheles gambiae sensu lato in a laboratory room and semi-field enclosure, were used to compare catch rates of odour-baited Suna traps and MM-X traps. The relative performance of the Suna trap, CDC light trap and MM-X trap as monitoring tools was assessed inside a human-occupied experimental hut in a semi-field enclosure. Use of the Suna trap as a tool to prevent mosquito house entry was also evaluated in the semi-field enclosure. The optimal hanging height of Suna traps was determined by placing traps at heights ranging from 15 to $105 \mathrm{~cm}$ above ground outside houses in western Kenya.

Results: In the laboratory the mean proportion of An. gambiae s.l. caught in the Suna trap was 3.2 times greater than the MM-X trap ( $P<0.001)$, but the traps performed equally in semi-field conditions ( $P=0.615)$. As a monitoring tool, the Suna trap outperformed an unlit CDC light trap $(P<0.001)$, but trap performance was equal when the CDC light trap was illuminated $(P=0.127)$. Suspending a Suna trap outside an experimental hut reduced entry rates by $32.8 \%$ $(P<0.001)$. Under field conditions, suspending the trap at $30 \mathrm{~cm}$ above ground resulted in the greatest catch sizes (mean 25.8 An. gambiae s.l. per trap night).

Conclusions: The performance of the Suna trap equals that of the CDC light trap and MM-X trap when used to sample An. gambiae inside a human-occupied house under semi-field conditions. The trap is effective in sampling mosquitoes outside houses in the field, and the use of a synthetic blend of attractants negates the requirement of a human bait. Hanging a Suna trap outside a house can reduce An. gambiae house entry and its use as a novel tool for reducing malaria transmission risk will be evaluated in peri-domestic settings in sub-Saharan Africa.
\end{abstract}

Keywords: Anopheles mosquito, Malaria vector, Suna trap, CDC light trap, MM-X trap, Attractant, Odour bait, Surveillance

\section{Background}

Effective monitoring of mosquito populations should provide information regarding the possible transmission intensity of mosquito-borne diseases in a given area at a particular time. Understanding vector population dynamics could provide early warning for an outbreak of disease or act as an outcome measure in evaluating the impact of a vector control programme $[1,2]$.

\footnotetext{
*Correspondence: alexandra.hiscox@wur.nl

'Laboratory of Entomology, Wageningen University and Research Centre, Wageningen, The Netherlands

Full list of author information is available at the end of the article
}

An ideal monitoring tool would sample without bias; i.e. the trap would collect mosquitoes representative of all species, ages and gonotrophic stages found in the environment of the trap. For the widest possible application the tool would be effective wherever human hosts are found, which may include domestic and peri-domestic environments in urban as well as rural settings, inside and outside houses. The trap would also be effective during the times of day when vectors are most active. Medical entomologists work towards the development of traps that meet as many of these requirements as possible [3-5].

Monitoring of malaria mosquitoes poses a number of specific challenges; during its lifecycle a mosquito will 
pass through both aquatic and terrestrial life stages, and different species may occupy vastly differing ecological niches [6-9]. The most efficient malaria vectors are closely associated with the domestic environment and bite humans in and around their dwellings, whilst other species are predominantly found outdoors and may feed on both humans and animals [10-12].

The feeding habits of mosquitoes may be exploited for surveillance purposes. Thus, methods have been developed to intercept mosquitoes while they are host seeking. Historically, the most commonly used tool for monitoring malaria vectors was the human landing catch (HLC). This approach is considered to provide the best measure of man-biting rate and peak time of biting in a specific time and place [13-17]. Given the potential for exposure of volunteers to infective mosquito bites, as well as nonstandardized trapping due to variation between the attractiveness of volunteers, and their ability to catch mosquitoes in the process of biting, an effective non-biased mosquito sampling tool, such as a trap, is needed.

Mechanical traps have been developed to substitute for the HLC [4]. Such traps may contain attractive stimuli that lure mosquitoes to the collection site. Because $\mathrm{CO}_{2}$ acts as a universal mosquito attractant, many traps are baited with this chemical [18]. For more selective mosquito species, additional volatile chemicals are added to the bait, significantly enhancing the catch [19-21].

At present, the most widely used trap for mosquito monitoring in and around the domestic environment is the CDC light trap (CDC LT) (John W. Hock company, Gainesville, FL). The CDC LT is generally used indoors, positioned beside a human-occupied bed net, without the addition of a synthetic chemical lure. Mosquitoes that are attracted to, but unable to reach, the human inside the bed net are caught when they fly around the trap [22,23]. The requirement for positioning the trap close to a human host means that the CDC LT is mainly limited to use indoors and is not an effective tool for monitoring the outdoor-biting population [23]. Studies comparing the performance of CDC LTs against HLC have reported widely variable results from different geographic locations [14,16,24,25].

Whilst the CDC LT has remained largely unchanged since the 1970s, the past decades have led to an increased understanding of which organic volatiles stimulate hostseeking mosquitoes to fly towards a host [26-28]. Traps baited with these odours have since formed an increasingly useful tool for monitoring mosquito populations. The Mosquito Magnet- $\mathrm{X}^{\bullet}(\mathrm{MM}-\mathrm{X})$ trap (American Biophysics corporation, North Kingstown, RI) is an odourbaited mosquito trap, which may be used outdoors or indoors [29-31] with mosquitoes attracted to a plume of odours and $\mathrm{CO}_{2}$ dispensed from the trap. Once a mosquito is close to the source of the odours, it is sucked into the trap by a counter-flow ventilation system [32]. Another odour-baited trap is the BG-Sentinel (Biogents AG, Germany) [33]. This suction trap disperses odours over a large surface, thus imitating convection currents of a host. Although widely used for dengue transmitting mosquitoes, the potential of the trap for collecting vectors of malaria has been recently explored [34].

A novel trap for malaria mosquito monitoring and control has been developed in collaboration between Biogents AG (Regensburg, Germany), the International Centre of Insect Physiology and Ecology (Mbita Point, Kenya) and the Laboratory of Entomology at Wageningen University and Research Centre (Wageningen, The Netherlands). The Suna trap is a new modification of the BG-Sentinel trap, but uses the same patented trapping technology. This paper describes the results of laboratory, semi-field and field studies to evaluate the performance of this new trap against the MM-X trap and the widely used CDC LT.

As well as using traps for mosquito monitoring, it has been suggested that an effective trap could also be used as a tool for mosquito control when used in combination with existing methods such as bed nets [35]. By daily removal trapping of mosquitoes, the size of a local vector population could be diminished, thus people would be exposed to fewer potentially infective bites. A lower entomological inoculation rate (EIR) would reduce the force of infection, bringing about a reduction in the basic reproductive number for a disease $\left(R_{0}\right)$ and possible elimination of a disease if $R_{0}$ is brought below 1 [1].

The aims of this study were to evaluate the relative trapping efficacy of the Suna trap, CDC LT and MM-X trap, and to assess whether mosquito house entry could be reduced by hanging a Suna trap outside a traditional mud-walled African house. Experiments were conducted in laboratory, semi-field and field conditions.

\section{Methods \\ Study sites}

The studies described here took place in the behavioural room of the Laboratory of Entomology at Wageningen University and Research Centre (The Netherlands), semifield screenhouses and the MalariaSphere at the Thomas Odhiambo Campus (TOC) of icipe (International Centre of Insect Physiology and Ecology, Mbita Point, western Kenya) $\left(00^{\circ} 25^{\prime} \mathrm{S}, 34^{\circ} 13^{\prime} \mathrm{E}\right)$ and in field conditions at Ahero, western Kenya $\left(00^{\circ} 34^{\prime} \mathrm{S}, 034^{\circ} 65^{\prime} \mathrm{E}\right)$.

The behavioural room at Wageningen University measures $3.8 \mathrm{~m}$ long, $3.7 \mathrm{~m}$ wide, $3.2 \mathrm{~m}$ high and contains a large netted chamber measuring $3 \mathrm{~m}$ in length, $2.5 \mathrm{~m}$ in width and $2.5 \mathrm{~m}$ in height (see Additional file 1 for layout diagram). A 15-Watt bulb directed upwards towards a white cotton sheet on the ceiling provided low-lux lighting (artificial moonlight). 
Dual choice experiments in semi-field conditions in Kenya were conducted in screen-walled greenhouses ("screenhouses") [36]. In these structures the glass had been removed from the walls and replaced by gauze. A large mosquito-netting cage (length $11 \mathrm{~m}$, width $7 \mathrm{~m}$, height $2.5 \mathrm{~m}$, with a $3 \mathrm{~mm}$ mesh-width) was suspended inside the screenhouse. The sand floor was watered daily in order to maintain high humidity levels.

Comparisons between the CDC LT, MM-X trap and Suna trap took place in the MalariaSphere [37] (see Additional file 2 for layout diagram). Briefly, a mudwalled, grass-thatched house was constructed in a screenhouse containing grasses, crops and other plants found growing in the local area (plantain banana, wild sage, black-jack, Parthenium weed, castor bean, Guinea grass and Napier grass) to mimic the conditions around a house in a typical Luo village of the area surrounding Lake Victoria in Kenya. Inside the house was a bed covered by an untreated bed net, allowing a human volunteer to sleep in the house at night. Whilst experiments were taking place, the door of the house was closed, thus the open eaves were the only house entry point for mosquitoes.

Field experiments to determine optimal height positioning of the Suna trap took place at Kigoche village in Kisumu County, western Kenya. Traps were suspended from overhanging roofs of mud-walled, metal-roofed houses with open eaves. Houses had not received indoor residual spraying (IRS) within the past six months and were located within $100 \mathrm{~m}$ of rice fields that were flooded during the time of the study (August-September 2012). Annual rainfall in this area ranges from 1000- $1800 \mathrm{~mm}$, temperatures fall between $17-32^{\circ} \mathrm{C}$ and relative humidity is between 44 and $80 \%$. Each house was occupied during the study with residents sleeping under insecticide-treated bed nets, as is standard practice for this region, and as advised by the Kenyan Ministry of Health.

\section{Mosquitoes}

The Anopheles gambiae sensu stricto (s.s.) mosquitoes used for laboratory experiments originated from Suakoko, Liberia and have been cultured at the Laboratory of Entomology (Wageningen, The Netherlands) since 1987. The colony is of the An. gambiae s.s. M form and is hereafter referred to as Anopheles coluzzii. The mosquitoes were reared in climate-controlled rooms at $27 \pm$ $1{ }^{\circ} \mathrm{C}, 80 \pm 5 \%$ relative humidity, with a 12 -hour light: 12 hour dark cycle. Adults emerged from pupae into gauzecovered cages measuring $30 \times 30 \times 30 \mathrm{~cm}$. Within the cages adults had access to a $6 \%(\mathrm{w} / \mathrm{v})$ glucose solution provided on filter paper. Females were blood fed daily and provided with moist filter paper on which to oviposit. Eggs were placed in tap water in plastic trays containing Liquifry No.1 fish food (Interpet Ltd., United Kingdom), larvae were fed Tetramin ${ }^{\odot}$ baby fish food
(Melle, Germany) and pupae were collected and allowed to emerge into BugDorm cages (MegaView Science, Taiwan).

The An. gambiae s.s. colony used during semi-field experiments in Kenya originated at Mbita Point and has been cultured at the icipe-TOC since 2001. The colony is of the An. gambiae s.s. S form and is hereafter referred to as An. gambiae. Larval rearing in Kenya took place under ambient conditions in screen-walled greenhouses. Pupae were collected on a daily basis and placed in cages measuring $30 \times 30 \times 30 \mathrm{~cm}$ to emerge. Once emerged, adults had access to $6 \%$ glucose $(\mathrm{w} / \mathrm{v})$ solution provided on filter paper and were blood fed three times a week. Eggs were laid on filter paper then transferred to plastic trays with filtered water from Lake Victoria. Emerged larvae were fed daily on Tetramin ${ }^{\oplus}$ baby fish food (Melle, Germany).

Adult females used in laboratory and field experiments were between five and eight days old, had never received a blood meal and were starved by providing access to only distilled water on cotton wool for 10-18 hours before experiments took place.

\section{The Suna trap}

The Suna trap, named after the Dholuo word for mosquito, consists of five main components (Figure 1); a funnel and ventilator section, carbon dioxide release pipe, perforated plastic base, netting catch bag, hanging tripod and conical plastic cover. When the trap is connected to a 12 volt power supply the ventilator rotates, sucking air up through the funnel at a rate of $3.1 \mathrm{~m} / \mathrm{s}$, thus opening the funnel shutter gate. As air circulates under the conical cover of the trap, volatiles from a synthetic chemical blend of attractants are released from the nylon strips suspended from the hanging tripod. The odour-saturated air is forced out of the trap through holes in the plastic base at a rate of $0.5 \mathrm{~m} / \mathrm{s}$. This generates a flow of attractants, which are carried away from the trap. In addition, a plume of $\mathrm{CO}_{2}$ diffuses from the $\mathrm{CO}_{2}$ release pipe, mimicking breath of a host. In effect, the combination of odours and $\mathrm{CO}_{2}$ forms a human surrogate.

Mosquitoes encountering these odours fly upwind towards the trap and, when they are in close proximity to the funnel, they are sucked into the trap through the ventilator. Inside the trap they are contained in the catch bag. When the power supply is turned off, the shutter gate automatically drops to a closed position due to a weighting mechanism and mosquitoes are unable to escape. Mosquitoes caught inside the trap die due to dehydration and lack of food.

\section{Comparison between the Suna trap and the MM-X trap in laboratory and semi-field conditions}

In the behavioural room in The Netherlands and in a semi-field screenhouse in Kenya, similar experimental 


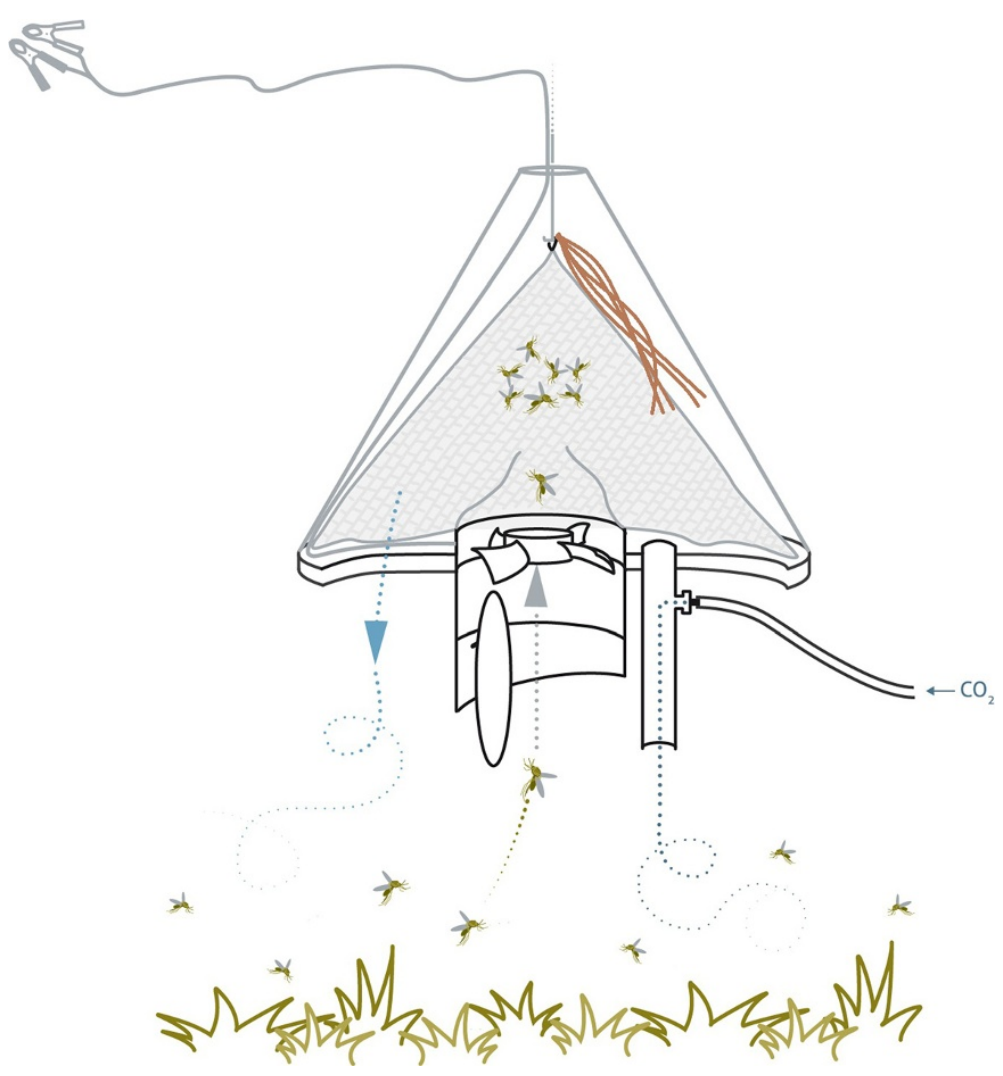

Figure 1 Cross-sectional schematic view of the Suna trap. When connected to a power supply the ventilator rotates and generates airflow under the cover of the trap. The air moves around an odour-bait (here shown as brown strips of nylon), which is suspended inside the trap between the catch bag and plastic trap cover. The air becomes saturated with odour that is attractive to mosquitoes. Air plumes leave the trap through holes in the trap base (blue arrow) and mosquitoes fly towards this attractive cloud of odour, as well as a plume of $\mathrm{CO}_{2}$, which is released through a pipe in the trap base. Mosquitoes that come close to the trap are sucked into the trap through the funnel and ventilator (grey arrow) and are captured in a bag where they die due to dehydration.

setups were used to carry out a dual-choice experiment comparing mosquito trapping efficacy of the Suna trap against the MM-X trap (see Additional file 1). During any given replicate of the experiment, one Suna trap and one MM-X trap were suspended simultaneously in opposite corners of either the behavioural room or the screenhouse. Suna traps were suspended at $30 \mathrm{~cm}$ above the ground, as demonstrated to be the most effective height for this trap during field experiments. MM-X traps were suspended at $15 \mathrm{~cm}$ above ground level [29]. The positions of the traps were alternated for each experimental replicate and mosquitoes were released from a point equidistant from the two traps. In The Netherlands and Kenya, both traps were baited with a blend of ammonia, L-lactic acid, tetradecanoic acid, 3-methyl-1-butanol and 1-butylamine [38]. In the behavioural room, pressurized $\mathrm{CO}_{2}$ was supplied from a cylinder at $250 \mathrm{cc} /$ min. In the semi-field setup, $\mathrm{CO}_{2}$ was produced through a yeast and molasses fermentation process $(250 \mathrm{ml}$ molasses, $17.5 \mathrm{~g}$ yeast, 2 litres water), shaken vigorously for 30 seconds [39].
In The Netherlands, 50 unfed female An. coluzzii were used for each experimental replicate and experiments were carried out during the mosquito dark photoperiod (artificially set between 00:00 h and 12:00 h) with a duration of one hour per replicate. In Kenya, 200 unfed female An. gambiae were released into the screenhouse at 20:00 $\mathrm{h}$ and the experiment was stopped at 06:30 $\mathrm{h}$ the following morning.

At the end of all laboratory and semi-field experiments traps were placed in a freezer at $-20^{\circ} \mathrm{C}$ in order to knock down mosquitoes for counting. Temperature and relative humidity were measured during all experimental replicates using a Tinytag ${ }^{\circ}$ Ultra data logger (model TGU1500, INTAB Benelux, The Netherlands). Any remaining mosquitoes died during the day because of exposure to high daytime temperatures and starvation.

\section{Comparison of the Suna trap, MM-X trap and CDC light trap under semi-field conditions}

The trapping efficacy of the Suna trap was compared against that of the MM-X trap and CDC LT under semi- 
field conditions in the MalariaSphere in Kenya. Over the course of two experimental series, each of 24 nights duration (24 nights March - April 2013 and 24 nights February - March 2014), one trap per night was suspended next to the foot end of a untreated bed net, occupied by a male, aged 30 years, inside the MalariaSphere experimental hut (see Additional file 2). Trap models were allocated randomly over the 24 nights of each experimental series with each trap used eight times over the course of the experiment.

The Suna trap and the MM-X trap were baited with the MB5 blend of attractants [38], and were supplied with $\mathrm{CO}_{2}$ produced through a process of yeast and molasses fermentation, as described above. The CDC LT remained without odour bait, according to the standard protocol for the use of this trap [24]. During the first series of experiments the light in the CDC LT was turned off, but during the second series of experiments the light in the CDC LT was on. Traps were suspended at heights above the ground that have previously been demonstrated to be most effective for each trap. The Suna trap was positioned with the funnel opening at $30 \mathrm{~cm}$ above ground level (see results described in this paper), the MM-X trap was suspended $15 \mathrm{~cm}$ above the ground $[29,31]$ and the CDC LT was suspended with the fan section at $50 \mathrm{~cm}$ above the ground [30].

Each night at 20:00 h, 200 unfed female An. gambiae were released into the MalariaSphere (50 from each of the four release points indicated in Additional file 2). Mosquitoes were released from four release points in order to simulate the possibility of mosquitoes approaching a house from multiple breeding sites under field conditions, and to avoid directional bias of mosquitoes accessing the hut when only one release point is used. The MalariaSphere remained closed until 06:30 h the following morning when the experiment was stopped. During each night of the study the temperature $\left({ }^{\circ} \mathrm{C}\right)$, relative humidity (\%) and total rainfall $(\mathrm{mm})$ were recorded.

At the time of stopping the experiment, the number of females remaining in each of the release cups was counted. The number of females resting on the walls inside the house was counted as a measure of mosquitoes entering the house but not entering the trap.

\section{The performance of the Suna trap as a tool to reduce mosquito house entry in semi-field conditions}

Measurement of a possible reduction in mosquito house entry that could be achieved by suspending a Suna trap outside a house was performed in the MalariaSphere, following a similar experimental setup as described in the previous experiment.

During each of 32 experimental nights 200 unfed female $A n$. gambiae were released into the MalariaSphere at 20:00 $\mathrm{h}$ and experiments were concluded at 06:30 h the following morning. As in previous experiments, an adult male volunteer slept underneath an untreated mosquito net on a bed inside the MalariaSphere hut. On alternate nights a Suna trap was hung outside the house at $30 \mathrm{~cm}$ above ground level (see Additional file 2 for trap positioning). As described above, the trap was baited with the MB5 blend of attractants and $\mathrm{CO}_{2}$ produced by yeast and molasses fermentation. On subsequent nights no trap was hung outside the house. On all nights a CDC LT with the light off was hung inside the house at a height of $50 \mathrm{~cm}$ above ground, beside the foot end of the bed. The CDC LT was not baited with a synthetic lure, as is standard for the use of this trap.

During every night of the experiment, the number of mosquitoes captured inside the CDC LT was counted, as well as the number of females resting on the interior walls of the MalariaSphere house. This provided an estimate of the number of mosquitoes entering the house overnight. On nights when the Suna trap was positioned outside the house, the number of mosquitoes captured in this trap was also counted.

\section{Study to determine the optimal height positioning of the Suna trap under field conditions}

A number of Suna trap prototypes were acquired in August 2012 and these traps were used to conduct a study into the optimal height positioning of the traps under field conditions. Eight houses were selected for inclusion in the study with a single Suna trap hung outside each of seven houses during every experimental night. One MM-X trap was used as a control on the eighth house; this trap was suspended at $15 \mathrm{~cm}$ above ground level according to previously established optimal height positioning for this trap [29]. Seven Suna traps were positioned at 15, 30, 45, 60, 75, 90 and $105 \mathrm{~cm}$ above ground level. The maximum height was as high as it was possible to suspend a trap before it would have been above the roof level of a house. Trap heights were rotated on a nightly basis so that every trap type + height combination was tested four times at each house - a total of 256 trap nights (32 experimental nights).

Traps were set at dusk (around 18:30 h) and collected at around 07:00 $\mathrm{h}$ the following morning. All traps were baited with the MB5 lure [38], as well as $\mathrm{CO}_{2}$ produced through fermentation of molasses. Upon returning to the field laboratory, traps were placed in a $-20^{\circ} \mathrm{C}$ freezer to knock down mosquitoes for counting and identification to species-group level on the basis of morphological characteristics [40].

\section{Statistical analysis \\ Suna trap compared with MM-X trap in laboratory and semi-field conditions (dual choice experiments)}

The mean response rate was calculated as the mean proportion (\%) of released females captured in either or 
both traps during each experimental replicate. Mean catch sizes were calculated for each trap type. Independent effects of trap position, temperature or humidity on catch size were tested using a generalized linear model with log link function and negative binomial distribution. Whether the distribution of mosquitoes between the two traps differed from a 1:1 distribution was estimated using a $X^{2}$ test with two-tailed P-value.

\section{Suna trap sampling efficacy under semi-field conditions}

Mean catch sizes for the CDC LT, MM-X trap and Suna trap were calculated. The effect of trap type, rainfall, temperature and humidity as independent predictors of the number of mosquitoes caught in a trap were modelled using generalized linear models with a Poisson distribution and log link function. The effect of each predictor was modelled independently (univariate analysis), and predictors with $\mathrm{P}<0.1$ were included in a multivariable model of trap performance (number of mosquitoes caught in a trap). The association between number of mosquitoes found resting on the interior the walls of the house and each predictor variable was also assessed in the same way.

\section{Suna trap as an intervention tool - prevention of mosquito house entry}

House entry rates were estimated as mean CDC LT catch sizes and mean number of mosquitoes resting on the interior walls of the house per study night. Ultimately these two values were combined to give a measure of house entry, and mean house entry rates were compared between nights when the Suna trap was suspended outside the house (intervention) and when it was absent (control). Univariate analyses tested for associations between mosquito house entry with intervention status, temperature and humidity. A multivariable GLM with Poisson distribution and log link function was constructed using intervention status and relative humidity as predictors of mosquito house entry.

\section{Optimal height positioning of the Suna trap in field conditions}

Species composition of female mosquitoes was calculated as the proportion (\%) that each species group (Anopheles gambiae sensu lato, Anopheles funestus, Culex species) formed of the total female catch from all traps. Data were combined for unfed, fed and gravid females. Anticipated predictors of catch size (trap type + height, sampling location and night) were tested for an association with catch size using a generalized linear model with log link function. Variables that were significant in univariate analysis $(\mathrm{P}<0.1)$ were included in a multivariable model. Estimated marginal means (EMM) were calculated for each trap type + height position for An. gambiae s.l., An. funestus and Culex females. All statistical analyses were performed using SPSS statistics version 19 (IBM corporation).

\section{Results}

Comparing the performance of the Suna trap and MM-X trap in a dual-choice experiment (laboratory and semi-field) Across 14 experimental replicates, a total of 700 female $A n$. coluzzii were released into the behavioural room at Wageningen University. The average temperature was $26.7^{\circ} \mathrm{C}\left(\min 25.0^{\circ} \mathrm{C}, \max 28.0^{\circ} \mathrm{C}\right)$ and average relative humidity $(\mathrm{RH})$ was $62.3 \%$ (min 50\%, max 73\%).

The mean response rate was $85.7 \%$ ( \pm 3.0 standard error of the mean). The mean catch in the MM-X trap was $10.4( \pm 1.2 \mathrm{SE}$; a mean $20.7 \%$ of released females), and the mean catch in the Suna trap was $33.3( \pm 2.40 \mathrm{SE}$; a mean $66.0 \%$ of released females).

Under behavioural room conditions there was no evidence for positional bias, and temperature and $\mathrm{RH}$ were not linearly associated with catch size. The mean proportion of released mosquitoes caught in the Suna trap was 3.2 times greater than the proportion caught in the MM-X trap (Figure 2). The total Suna trap catch $(\mathrm{N}=$ 466 females) differed significantly compared with the catch in the MM-X trap ( $\mathrm{N}=146$ females) $\left(X^{2}=167.3,1\right.$ d.f., $\mathrm{P}<0.001)$.

Over the course of 16 nights (32 trap nights) 3,200 An. gambiae were released into the screenhouse in Kenya. The average temperature was $24.0^{\circ} \mathrm{C}\left(\min 20.0^{\circ} \mathrm{C}\right.$, max $28.4^{\circ} \mathrm{C}$ ) and average $\mathrm{RH}$ was $73.0 \%(\min 58.8 \%$, $\max$ $89.2 \%)$. Both traps functioned normally during all replicates and all data points were included in the analysis.

The mean response rate in the screenhouse was $71.1 \%$ $( \pm 4.76 \mathrm{SEM})$. The mean catch in the MM-X trap was 70.4 female An. gambiae ( \pm 7.6 SEM; $35.2 \%$ of released females) while the mean Suna trap catch size was 71.9 females $( \pm 7.5$ SEM; $35.9 \%$ of released females). Catch sizes for both trap types were positively skewed, MM-X trap catch sizes ranged from 31 up to 137 females per night and the Suna trap ranged from 31 to 138 females in a single night. There was no evidence that trap position in the screenhouse had a significant impact on mean mosquito catch sizes. Average nightly temperature and $\mathrm{RH}$ were also not found to be associated with catch size.

The mean proportion of released mosquitoes caught in each trap per night was calculated (Figure 2) and the total number of mosquitoes trapped in the Suna trap $(\mathrm{N}=$ $1150)$ compared with the MM-X trap $(\mathrm{N}=1126)$ was not found to differ significantly from a $1: 1$ distribution $\left(X^{2}=\right.$ 0.253, 1 d.f., $P=0.615$ ).

\section{Assessing the performance of the Suna trap as a monitoring tool - relative sampling efficacy} During each of the two experiments, both of 24 nights duration, 4,800 female An. gambiae were released in the 

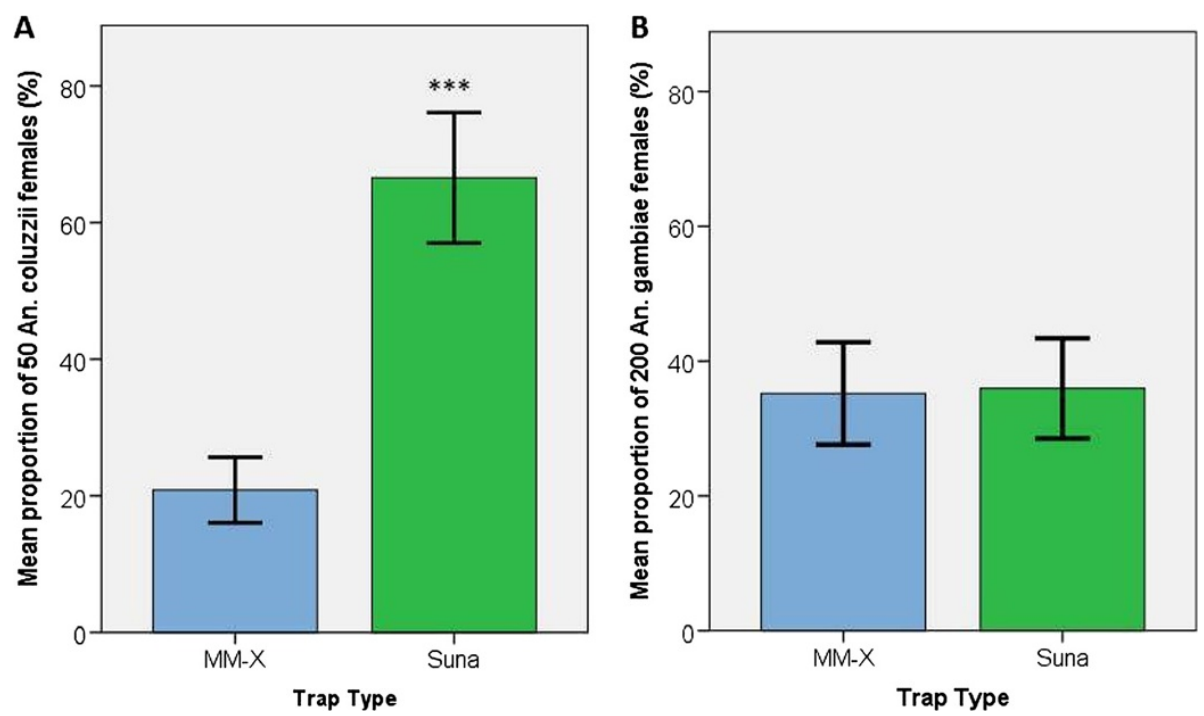

Figure 2 Mean proportion of females caught in each trap type in A: laboratory conditions ( $\mathrm{n}=\mathbf{5 0}$ females released per replicate), B: semi-field conditions $\left(\mathbf{n}=\mathbf{2 0 0}\right.$ females per replicate). Error bars indicate \pm 2 SEM. ${ }^{* *}$ indicates $P<0.001$ for a difference in the distribution of mosquitoes between the two traps.

MalariaSphere. During the first experiment (CDC LT light off) $49.6 \%$ of these females were caught in a trap, and $1.3 \%$ were found resting on the walls inside the MalariaSphere house when the experiment ended in the morning. During the second repetition of the experiment (CDC LT illuminated), $46.2 \%$ of females were trapped and $2.1 \%$ were found resting on the interior walls of the house the following morning. Mosquito flight responses were good, with only 12 females (first series of experiments) and 26 females (second series) remaining in release cups in the morning after experiments. During the course of both experiments all traps functioned normally and climatic conditions were in a range that is normal for this region. All data points were included in the analysis.

In the first series (CDC LT light off), mean catch sizes were greater in the MM-X trap (mean 108.4 \pm 6.0 SEM) and the Suna trap (mean 108.8 \pm 5.5 SEM) compared with the CDC light trap (mean $80.6 \pm 8.4$ SEM). The distribution of catch sizes differed between the trap types (see Additional file 3), with the CDC LT having the smallest range of catch sizes. The number of mosquitoes captured was positively skewed for all three types of trap. In the second series (CDC LT illuminated), the mean catch size was greatest in the CDC LT (mean 103.4 \pm 3.6 SEM), followed by the Suna trap (mean $95.8 \pm$ 3.5 SEM) with the lowest mean catch in the MM-X trap (mean 77.9 \pm 3.1 SEM). Catch sizes for the CDC LT and Suna trap were slightly negatively skewed, whereas MM-X trap catch sizes were slightly positively skewed.

During the first series of experiments there was some indication that temperature and humidity had a small but significant effect on catch size but, as temperature and rainfall both contribute to environmental humidity, in the final analysis only humidity was included as a climatic predictor of catch size. During the second series using the CDC LT with light on, there was no evidence of a univariate association between temperature, humidity and catch size.

After accounting for humidity in the MalariaSphere, there was strong evidence to suggest that female $A n$. gambiae were more likely to be trapped using a Suna trap $(\mathrm{RR}=1.351,95 \% \mathrm{CI}: 1.22-1.50, \mathrm{P}<0.001)$ or the MM-X trap ( $R R=1.343,95 \%$ CI: $1.21-1.49, \mathrm{P}<0.001)$ compared with a CDC LT with the light off (Figure 3). In the second experiment, the performance of the Suna trap was found to be equivalent to that of an illuminated CDC LT $(R R=0.926,95 \%$ CI: $0.840-1.022, P=0.127)$, whilst catch sizes in the MM-X trap were significantly lower than in the illuminated CDC LT ( RR $=0.753,95 \%$ CI: $0.679-0.836, \mathrm{P}<0.001$ ) (Figure 3 ).

In order to assess whether the number of mosquitoes entering the house, but not caught in a trap, differed according to trap method, the number of females resting on the interior walls of the house in the morning was compared between nights during which each trap type was used (see Table 1). The effect of temperature, rainfall and humidity on indoor resting was also investigated. Univariate analyses indicated that increased humidity was associated with lower indoor resting densities $(\mathrm{RR}=$ 0.961, 95\% CI: $0.925-0.999, \mathrm{P}=0.045)$. In the second experiment (CDC LT illuminated) there was no evidence of an association between temperature or humidity on indoor resting. 

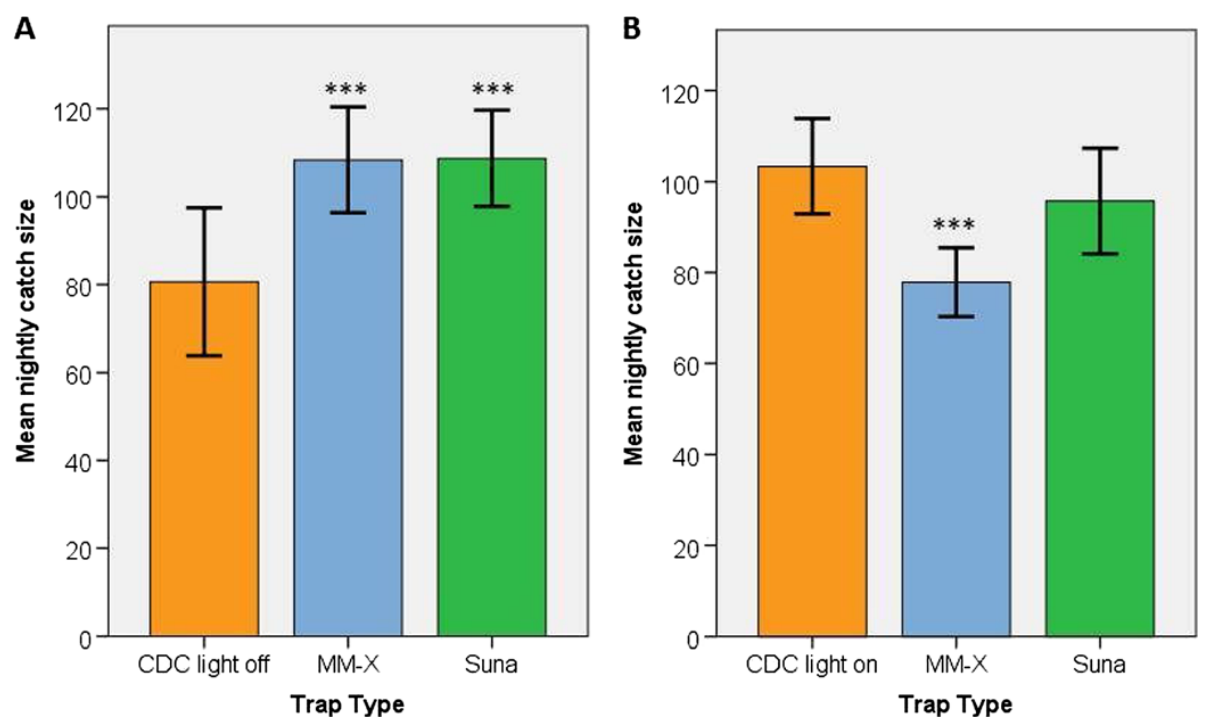

Figure 3 Mean nightly catch sizes in the A: CDC LT (light off), MM-X trap and Suna trap, B: CDC LT (light on), MM-X trap and Suna trap during experiments in the MalariaSphere. (Error bars represent $\pm 2 \mathrm{SEM}, \mathrm{N}=8$ trap nights for each trap during each series of experiments, $\mathrm{n}=200$ female An. gambiae released during each experimental night). ${ }^{* *}$ indicates $\mathrm{P}<0.001$ for a difference in catch size, relative to the CDC LT.

Multivariable analysis adjusted for reduced indoor resting with increased humidity in the first experiment, indicated that there was no evidence for a difference in indoor resting with the MM-X trap $(\mathrm{RR}=0.636,95 \% \mathrm{CI}: 0.355-$ 1.137, $\mathrm{P}=0.127)$ or Suna trap $(\mathrm{RR}=0.559,95 \% \mathrm{CI}: 0.303-$ $1.030, \mathrm{P}=0.062)$ compared with the unlit CDC LT. In the second experiment, trap type was also not a significant determinant of residual indoor resting (MM-X trap $R R=$ 1.583, 95\% CI: $0.950-2.639, \mathrm{P}=0.078$, Suna trap $\mathrm{RR}=$ 1.542, 95\% CI: $0.922-2.577, \mathrm{P}=0.099)$.

The performance of the Suna trap as an intervention tool to reduce mosquito house entry in semi-field conditions Over the course of 32 nights, 6,400 unfed female $A n$. gambiae were released in the MalariaSphere. A total of $3,573(55.8 \%)$ of these females were recaptured in either the Suna trap, the CDC LT or resting on the interior walls of the house. Mosquito flight activity was good with only $31(0.48 \%)$ females remaining in any of the four release cups during the morning after an experiment. As in the previous experiment it was assumed that survival of a female to the following day was unlikely.

During the 32 nights of the experiment, temperature and humidity levels were normal for the time of year (mean nightly temperature $23.7^{\circ} \mathrm{C}$, min $19.1^{\circ} \mathrm{C}$, max $29.4^{\circ} \mathrm{C}$; mean $\mathrm{RH} 73.3 \%$, min 37.0\%, max 99.0\%; mean rainfall $5.5 \mathrm{~mm}$, min $0 \mathrm{~mm}, \max 32.7 \mathrm{~mm}$ ). All traps functioned normally throughout the course of the experiment and all data points were included in the analysis. The distributions of CDC LT catch sizes (as a measure of mosquito house entry) were slightly positively skewed, with a narrower range of catch sizes when the Suna trap was hung outside the house (intervention status), compared with when there was no trap outside the house (control status).

When the Suna trap was not suspended outside the house (control situation) a mean 84.1 females entered the CDC LT inside the house each night $( \pm 6.3$ SEM, $N=16$ trap nights), but when the Suna trap was in place outside the house the mean CDC LT catch reduced to $56.7 \mathrm{fe}$ males per night $( \pm 4.0$ SEM).

Table 1 Mean indoor resting densities of An. gambiae females during trap comparison experiments in the MalariaSphere

\begin{tabular}{lllll}
\hline Experiment & Trap type & Mean indoor resting density (per night) & SEM & P value \\
\hline 1 & CDC LT light off & 3.5 & 0.7 & - \\
& MM-X & 2.3 & 0.5 & 0.127 \\
& Suna & 2.0 & 0.5 & 0.062 \\
& CDC LT light on & 3.0 & 0.6 & - \\
& MM-X & 4.8 & 0.8 & 0.078 \\
& Suna & 4.6 & 0.8 & 0.099 \\
\hline
\end{tabular}

Means in experiment 1 are adjusted for humidity. SEM indicates 1 standard error of the mean, - indicates comparison group for analysis. 
The mean number of $A n$. gambiae found resting inside on the walls of the MalariaSphere house was also reduced when the Suna trap was hung outside the house compared with when no Suna trap was used (control mean 3.56, \pm 0.4 SEM, intervention mean 2.25, \pm 0.2 SEM).

As both CDC LT catch sizes and indoor resting were reduced by suspending a Suna trap outside the house, these two outcome variables were combined to give a single measure of house entry rate per night (sum of CDC LT catch and indoor resting catch) and this measure was used for subsequent analyses.

After adjusting for humidity, there was strong evidence that suspending a Suna trap outside the MalariaSphere house was associated with a $32.8 \%$ reduction in An. gambiae house entry (CDC LT + indoor resting catch), relative to the control situation where there was no trap positioned outside the house (estimated marginal mean $(E M M)$ house entry for control $=87.7 \pm 2.3$ $\mathrm{SEM}$, for intervention $=58.9 \pm 1.9 \mathrm{SEM} ; \mathrm{RR}=0.671,95 \%$ CI: $0.618-0.729, \mathrm{P}<0.001$ ) (Figure 4).

\section{Optimal height positioning of the Suna trap under field conditions}

Over 256 trap nights a total of 7,620 female and 269 male mosquitoes were captured in traps outside houses in Ahero. An. gambiae s.l. formed $41.4 \%$ of the total

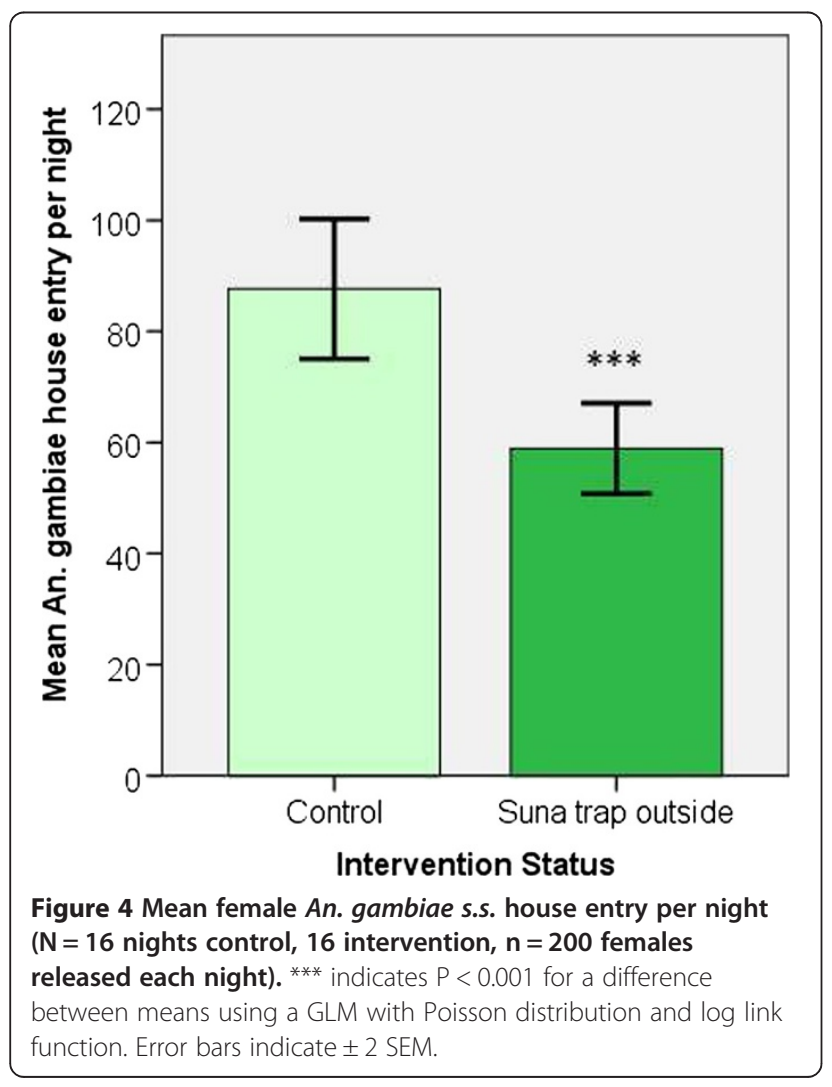

female catch (mean catch per trap per night $=12.3 \pm 1.5$ SEM), and An. funestus group comprised $15.5 \%$ of the female catch $($ mean $=4.6 \pm 0.3 \mathrm{SEM})$. The remainder of the female catch comprised of Culex spp (17.0\%), Mansonia spp (23.9\%) and non-identifiable specimens (2.2\%).

The house where the trap was positioned was associated with catch size, with mean nightly catch size per house ranging from $5.4( \pm 1.1 \mathrm{SEM})$ to 15.7 ( \pm 2.9 SEM) An. gambiae s.l. (EMM adjusted for trap type + height and house). Study night was also associated with catch size and was included in the multivariable analysis of An. gambiae s.l. catch data.

Comparison of catch sizes between traps, adjusting for house and night of sampling in multivariable analysis, revealed that there was no statistically significant difference between $A n$. gambiae s.l. catch size in the Suna trap at $15 \mathrm{~cm}$ or $30 \mathrm{~cm}$ above the ground, relative to the MM-X trap suspended at $15 \mathrm{~cm}$ (EMM Suna catch $15 \mathrm{~cm}=13.8, \mathrm{RR}=0.617,95 \% \mathrm{CI}: 0.366-1.039, \mathrm{P}=$ 0.069; EMM Suna $30 \mathrm{~cm}=25.8, R R=1.152,95 \% \mathrm{CI}$ : $0.682-1.949, \mathrm{P}=0.597$, EMM MM-X catch $=22.4, \pm$ 4.2 SEM). With each successive $15 \mathrm{~cm}$ height increase above $30 \mathrm{~cm}$, catch sizes in the Suna trap decreased and traps suspended with the ventilator opening at $45 \mathrm{~cm}$ and higher above the ground were significantly less likely to catch An. gambiae s.l. than the MM-X trap at $15 \mathrm{~cm}$ (see Figure 5).

After adjusting for house, the greatest mean $A n$. funestus catch sizes were in the MM-X trap at $15 \mathrm{~cm}$ above ground level $(\mathrm{EMM}=6.7 \pm 1.3 \mathrm{SEM})$, but $A n$. funestus catch sizes in the Suna trap at 15, 30, 45, 60 and $75 \mathrm{~cm}$ were not significantly lower than those of the MM-X trap (Figure 5). At 90 and $105 \mathrm{~cm}$ above the ground $A n$. funestus catch sizes in the Suna trap were lower than for the MM-X trap at $15 \mathrm{~cm}$ above the ground (Suna $90 \mathrm{~cm}$ $\mathrm{RR}=0.508, \quad 95 \%$ CI: $0.293-0.883, \quad \mathrm{P}=0.016$, Suna $105 \mathrm{~cm} \mathrm{RR}=0.438,95 \% \mathrm{CI}: 0.251-0.763, \mathrm{P}=0.004)$. Houses varied in their degree of attraction to An. funestus, with adjusted mean catch sizes ranging from 2.9 $( \pm 0.6 \mathrm{SEM})$ to $6.2( \pm 1.2 \mathrm{SEM})$ females per night. Anopheles funestus catch size was not found to be significantly associated with study night.

After adjusting for house, maximum catch sizes for Culex females were obtained using the MM-X trap at $15 \mathrm{~cm}$ above the ground $(\mathrm{EMM}=9.4, \pm 1.8 \mathrm{SEM})$ and the Suna trap at $30 \mathrm{~cm}$ above ground level $(\mathrm{EMM}=8.8, \pm$ 1.7 SEM). The difference between these catch sizes was not statistically significant $(\mathrm{RR}=0.934,95 \% \mathrm{CI}: 0.547$ $1.596, \mathrm{P}=0.803)$. Culex catch sizes in the Suna trap at 15 , 45, 60, 75, 90 and $105 \mathrm{~cm}$ above ground level were all significantly lower than in the MM-X trap at $15 \mathrm{~cm}$ above the ground ( $\mathrm{P}=0.017, \mathrm{P}=0.001, \mathrm{P}<0.001, \mathrm{P}<0.001, \mathrm{P}<$ $0.001, \mathrm{P}<0.001$ respectively) (Figure 5 ). Mean catch sizes by house ranged from $2.1( \pm 0.46$ SEM $)$ up to $9.8( \pm 1.8$ 


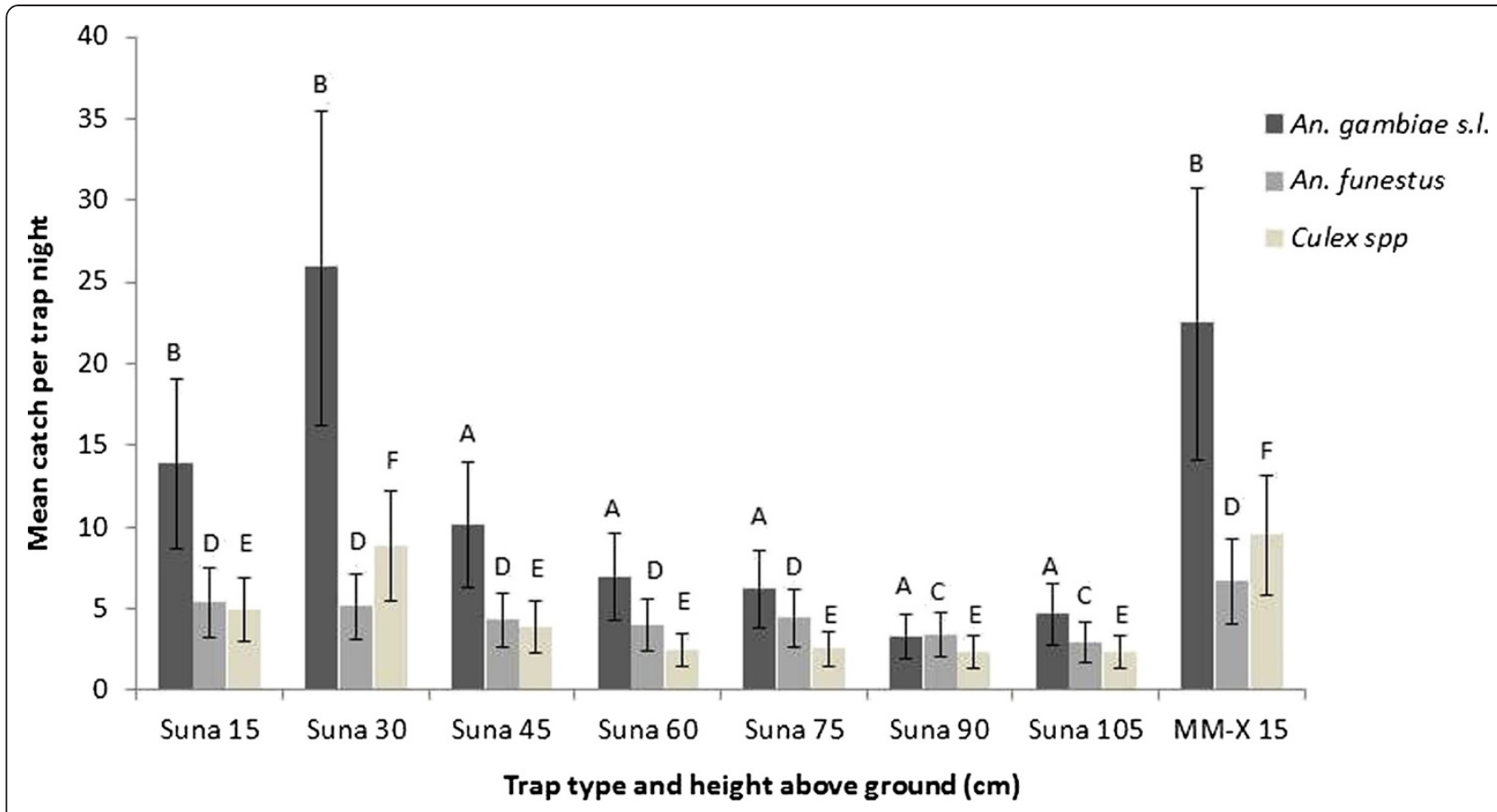

Figure 5 Estimated marginal mean catch sizes for female mosquitoes caught in Suna traps at varying heights above ground, and in an MM-X trap positioned at $15 \mathrm{~cm}$ above the ground, outside houses in the field. Means are adjusted for day of sampling (An. gambiae s.l. only) and house (all species). Error bars represent \pm 2 SEM. Different letters above bars indicate significant differences in catch sizes (A and $\mathbf{B}$ for An. gambiae s.l., C and $\mathbf{D}$ for An. funestus, $\mathbf{E}$ and $\mathbf{F}$ for Culex spp).

SEM) and study night was not significantly associated with Culex catch size.

\section{Discussion}

These results describe for the first time an evaluation of the Suna trap as a tool for trapping host-seeking mosquitoes, and as an intervention tool against An. gambiae house entry. It has been demonstrated that, under laboratory and semi-field conditions, the performance of the Suna trap surpasses or is equivalent to that of the MM-X trap. When positioned in an experimental hut in semi-field conditions the Suna trap is more efficacious than an unlit CDC LT, and equivalent in performance to a lit CDC LT. This research has shown that the Suna trap effectively collects mosquitoes outside houses in the field, in numbers that are equivalent to those caught in the MM-X trap. In addition, positioning the Suna trap outside an experimental hut in semi-field conditions, reduces the number of mosquitoes entering a hut occupied by a human.

Under laboratory conditions, the enhanced performance of the Suna trap, relative to the MM-X trap, could be explained by the wider plume of odour dispersed by the Suna trap at point of origin, which probably attracts more mosquitoes than the MM-X trap. In addition, it is expected that, once in close proximity to the Suna trap, mosquitoes are more likely to be sucked inside as the airflow of the Suna trap is greater than that of the MM$\mathrm{X}$ trap. Under semi-field and field conditions the trapping efficacy of the Suna trap and MM-X trap were equal. It is assumed that natural dispersal of the air plume, and its odorous components, combined with the constant shifting direction of the prevailing wind [41], create similar odour fronts for the mosquitoes to respond to [42], and that the effect of the wider point of origin odour plume in the Suna trap compared with the MM-X trap, is reduced. The mosquitoes used for experiments in the laboratory were An. coluzzii, while those used in semi-field experiments were An. gambiae s.s., but as the difference between forms $\mathrm{M}$ and $\mathrm{S}$ occurs in a small region of the $\mathrm{X}$ chromosome and both forms are anthropophilic it is not expected that this would contribute to a difference in response to the Suna trap.

Despite the equivalent performance of the two traps under field conditions, the MM-X trap was developed as a research tool and is currently not commercially available. The Suna trap provides a good alternative for the MM-X trap. The construction of this trap is technologically much simpler than that of the MM-X trap, rendering it a cheaper, but equally effective tool for sampling mosquitoes.

During the course of this study the relative performance of the CDC LT was found to be higher when the lamp was illuminated compared with when it was not 
illuminated. The amount by which the performance was increased could not be directly quantified as the two experiments were conducted nine months apart, but this finding is in line with those of Costantini and Mweresa who also found that illuminated light traps had greater catch sizes compared with unlit traps $[23,43]$. In comparison with the CDC LT, both lit and unlit, the Suna trap formed a good tool for sampling mosquitoes from inside a house occupied by a human sleeping under a bed net. As it has previously been demonstrated that the CDC LT is not an effective tool for monitoring outdoor biting mosquitoes [23], the traps were not compared outdoors.

In some settings the CDC LT has been considered as a proxy for the HLC, with catch sizes from the two methods being proportional to one another [24]. It can be inferred from the results described here that the Suna trap and MM-X trap baited with the MB5 blend of odours and $\mathrm{CO}_{2}$, provide an effective alternative for the CDC LT (beside a human-occupied bed net) and the relative catch size could, therefore, also be related to that of the HLC for An. gambiae.

The use of odour-baited traps, such as the Suna trap, carries an advantage over the more traditionally used CDC LT when used as a tool for estimating changes in possible human biting rate and background mosquito population density. Host-seeking mosquitoes are specifically attracted to the trap because the odours emitted mimic those of a human host [20,31,44]. Additionally the Suna trap is an effective tool for outdoor use, which does not apply in the case of the CDC LT. By using a standardized odour bait, the Suna trap is expected to exhibit a consistent relative sampling efficacy both indoors and outdoors throughout the night, as under stable environmental conditions the odours are released at a constant rate. Thus, this new trap holds great potential to form a replacement for the HLC, which has significant associated health risks and is subject to inter-individual variation in attractiveness to mosquitoes [45], as well as ability of volunteers to aspirate mosquitoes during a HLC [46].

As well as establishing that Suna traps are an effective means of sampling mosquitoes that entered a hut under semi-field conditions, it was shown that the Suna trap forms an excellent tool for sampling mosquitoes outside houses in a rice-growing area of western Kenya. The majority of anopheline mosquitoes sampled during this study belonged to the An. gambiae complex, and previous studies conducted in the same area identified all, or 99\%, of An. gambiae s.l. collected from this village as Anopheles arabiensis $[43,47]$. This indicates that the Suna trap baited with the five-component blend of odours and $\mathrm{CO}_{2}$ is an effective tool for sampling this member of the An. gambiae complex, as well as $A n$. coluzzii and An. gambiae s.s. As recent studies have demonstrated shifts towards outdoor biting among populations of An. gambiae s.l. and An. funestus in Tanzania and Equatorial Guinea [48,49], and there is a growing awareness that many malaria vectors are exophilic [50], it becomes increasingly important to be able to monitor these vector populations outside houses. The Suna trap could form an ideal tool for this purpose.

During this field study to evaluate the optimal hanging height of Suna traps positioned outside houses, buildings of the same construction, in similar locations, and with equivalent occupancy rates and reported bed net usage were selected. Despite this, there was significant houseto-house variation in catch sizes. It is recommended that mosquito monitoring programmes sample host-seeking mosquitoes in a range of different locations in order to make accurate measures of population density. Suna traps provide the advantage that many traps, baited with the same odour, can be operated simultaneously with relatively low labour costs. There is no need for an operator or human volunteer to be present during the nocturnal catching period.

As well as demonstrating that the Suna trap could be used for mosquito monitoring inside a house, the semifield testing environment was used to demonstrate that suspending a Suna trap outside a house with a single occupant underneath a bed net could reduce An. gambiae house entry rates by $32.8 \%$, compared to the situation where a bed net is the only form of personal protection against mosquito bites. This estimate of odour-baited trap efficacy should be integrated into models, such as the one developed by Okumu and others [35], which could be used to estimate the potential efficacy of massmosquito trapping as an intervention against malaria control when used in combination with ITNs.

Similar to these findings, Smallegange et al. reported reductions in An. gambiae house entry of almost $80 \%$ when using odour-baited MM-X traps with yeastproduced $\mathrm{CO}_{2}$ in the MalariaSphere [51]. In contrast, Jawara and others [29] did not observe any reduction in house entry when using odour-baited MM-X traps outside experimental huts in the Gambia. Differences in environmental conditions, trap type and composition of the odour bait may explain these seemingly contrasting findings.

Other interventions against mosquito house entry, such as burning repellent plants, adding ceilings to houses or closure of the eaves, have reduced An. arabiensis and An. gambiae house entry rates by more than $70 \%$ [52-54], but these methods presumably divert mosquito bites away from members of the protected house towards unprotected members of the community. The Suna trap collects mosquitoes that are flying around the peri-domestic environment, thus the protective effect is 
expected to be communal. An additional advantage of odour-baited traps for vector control, compared with existing approaches such as insecticide-treated bed nets and indoor residual spraying, is the absence of an insecticide in the traps. An intervention based on masstrapping of mosquitoes will not contribute to alreadyincreasing levels of insecticide resistance that threaten the long-term success of other vector control techniques. Furthermore, when used outside a house, the Suna trap provides a means of targeting exophagic mosquitoes and outdoor malaria transmission, which has been recommended as an essential step towards eventual elimination of malaria where ITNs, IRS and case management alone are insufficient [50,55-57].

The SolarMal project [58] on Rusinga Island, western Kenya, aims to evaluate for the first time whether the mass deployment of odour-baited Suna traps can be used to control malaria in an area where bed nets and case management are the existing mainstays of malaria control. These semi-field investigations into reductions in mosquito house entry that can be achieved by suspending the Suna trap outside a traditional house yielded promising results and the next stage of evaluating the Suna trap as a tool for malaria control in the field is eagerly anticipated.

\section{Conclusions}

The sampling efficacy of the Suna trap equals that of the illuminated CDC LT, with the added advantage that it does not require the presence of a human volunteer and that it can also be used to sample mosquitoes outdoors. As the trap uses a standardized odour bait, the variation in catches caused by differential attractiveness of HLC volunteers, or human-baited CDC LTs, is avoided, thus enhancing opportunities for routine and objective mosquito monitoring. When hung outside an experimental house, entry by An. gambiae is significantly reduced, suggesting that daily removal trapping by the Suna trap could provide a new tool for controlling malaria transmission in and around the peri-domestic environment in villages of sub-Saharan Africa.

\section{Additional files}

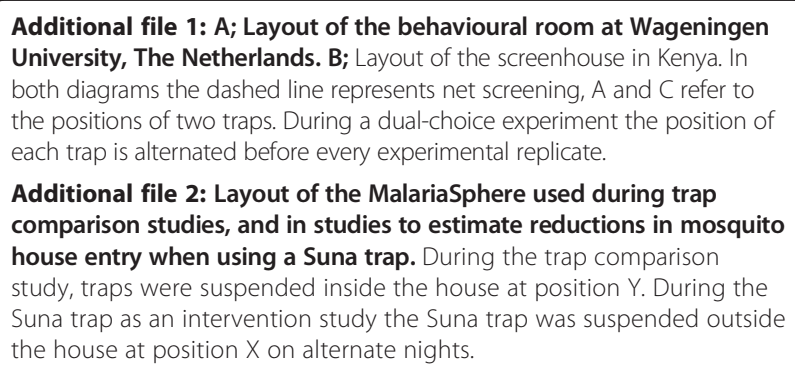

Additional file 2: Layout of the MalariaSphere used during trap comparison studies, and in studies to estimate reductions in mosquito house entry when using a Suna trap. During the trap comparison study, traps were suspended inside the house at position $Y$. During the Suna trap as an intervention study the Suna trap was suspended outside the house at position $X$ on alternate nights.

Additional file 3: A: Boxplot showing the minimum, first quartile, median, third quartile and maximum catch size for $A$ : the CDC LT (light off), MM-X trap and Suna trap ( $N=8$ trap nights for each type of trap). B: the CDC LT (light on), MM-X trap and Suna trap ( $N=8$ trap nights for each type of trap.

\section{Abbreviations}

CDC LT: Centers for Disease Control light trap; EIR: entomological inoculation rate; EMM: estimated marginal mean; IRS: indoor residual spraying;

ITN: insecticide-treated bed net; MM-X trap: Mosquito Magnet- $X^{\circledR}$ trap; $\mathrm{RH}$ : relative humidity; RR: relative rate; SEM: standard error of the mean.

\section{Competing interests}

$\mathrm{AH}, \mathrm{BO}, \mathrm{AK}, \mathrm{CKM}, \mathrm{PO}, \mathrm{MG}, \mathrm{AR}, \mathrm{WRM}$ and WT declare that they have no competing interests. The association of MG and AR with Biogents did not affect the decision to publish the data presented here and these authors were not involved in the experimental study design.

\section{Authors' contributions}

$A H, W T, W R M, M G$ and $A R$ designed and developed the Suna trap. AH, BO, $A K, C K M$ and $P O$ designed and carried out the laboratory, semi-field and field experiments. AH and WT analysed the data. AH, WT and WRM drafted the manuscript. All authors read and approved the final manuscript before submission.

\section{Acknowledgements}

We thank Frans van Aggelen, André Gidding, Leon Westerd, Elisha Obudho and David Alila for the rearing of the mosquitoes, Dan Simiyu for his assistance during MalariaSphere studies and Niels Verhulst for helping with the setup of the laboratory experiments. We would also like to thank Charles A. Oketch and the residents of Kigoche village for allowing us to conduct our research around their homes. This study was funded by the COmON foundation, The Netherlands.

\section{Author details}

${ }^{1}$ Laboratory of Entomology, Wageningen University and Research Centre, Wageningen, The Netherlands. ${ }^{2}$ International Centre of Insect Physiology and Ecology (icipe), Nairobi, Kenya. ${ }^{3}$ Biogents AG, Regensburg, Germany. ${ }^{4}$ School of Biological Sciences, University of Nairobi, Nairobi, Kenya.

Received: 4 April 2014 Accepted: 26 June 2014

Published: 7 July 2014

\section{References}

1. Smith DL, McKenzie FE, Snow RW, Hay SI: Revisiting the basic reproductive number for malaria and its implications for malaria control. PLOS Biol 2007, 5:e42.

2. Kiware SS, Chitnis N, Devine GJ, Moore SJ, Majambere S, Killeen GF: Biologically meaningful coverage indicators for eliminating malaria transmission. Biol Lett 2012, 8:874-877.

3. Wong J, Bayoh N, Olang G, Killeen GF, Hamel MJ, Vulule JM, Gimnig JE: Standardizing operational vector sampling techniques for measuring malaria transmission intensity: evaluation of six mosquito collection methods in western Kenya. Malar J 2013, 12:143.

4. Rubio-Palis Y, Moreno JE, Sanchez V, Estrada Y, Anaya W, Bevilacqua M, Cardenas L, Martinez A, Medina D: Can Mosquito Magnet ${ }^{\circledR}$ substitute for human-landing catches to sample anopheline populations? Mem Inst Oswaldo Cruz 2012, 107:546-549.

5. Hapairai LK, Joseph H, Sang MAC, Melrose W, Ritchie SA, Burkot TR, Sinkins $\mathrm{SP}, \mathrm{Bossin} \mathrm{HC}$ : Field evaluation of selected traps and lures for monitoring the filarial and arbovirus vector, Aedes polynesiensis (Diptera: Culicidae), in French Polynesia. J Med Entomol 2013, 50:731-739.

6. Silver JB: Mosquito Ecology: Field Sampling Methods. 3rd edition. Dordrecht: Springer; 2008.

7. Jude PJ, Dharshini S, Vinobaba M, Surendran SN, Ramasamy R: Anopheles culicifacies breeding in brackish waters in Sri Lanka and implications for malaria control. Malar J 2010, 9:106.

8. Fillinger $\mathrm{U}$, Sombroek $\mathrm{H}$, Majambere $\mathrm{S}$, van Loon $\mathrm{E}$, Takken W, Lindsay SW: Identifying the most productive breeding sites for malaria mosquitoes in The Gambia. Malar J 2009, 8:62.

9. Dutta P, Khan SA, Bhattarcharyya DR, Khan AM, Sharma CK, Mahanta J: Studies on the breeding habitats of the vector mosquito Anopheles 
baimai and its relationship to malaria incidence in Northeastern region of India. Ecohealth 2010, 7:498-506.

10. Tirados I, Costantini C, Gibson G, Torr SJ: Blood-feeding behaviour of the malarial mosquito Anopheles arabiensis: implications for vector control. Med Vet Entomol 2006, 20:425-437.

11. Sinka ME, Bangs MJ, Manguin S, Coetzee M, Mbogo CM, Hemingway J, Patil AP, Temperley WH, Gething PW, Kabaria CW, Okara RM, Van Boeckel T, Godfray HCJ, Harbach RE, Hay SI: The dominant Anopheles vectors of human malaria in Africa, Europe and the Middle East: occurrence data, distribution maps and bionomic precis. Parasit Vectors 2010, 3:117.

12. Takken W, Verhulst NO: Host Preferences of Blood-Feeding Mosquitoes. Annu Rev Entomol 2013, 58:433-453.

13. Zimmerman RH, Lounibos LP, Nishimura N, Galardo AKR, Galardo CD, Arruda ME: Nightly biting cycles of malaria vectors in a heterogeneous transmission area of eastern Amazonian Brazil. Malar J 2013, 12:262.

14. Overgaard HJ, Saebo S, Reddy MR, Reddy VP, Abaga S, Matias A, Slotman MA: Light traps fail to estimate reliable malaria mosquito biting rates on Bioko Island, Equatorial Guinea. Malar J 2012, 11:56.

15. Le Goff G, Carnevale P, Robert V: Comparison of catches by landings on humans and by $C D C$ light traps for sampling of mosquitoes and evaluation of malaria transmission in South Cameroon (in French). Ann Soc Belg Med Trop 1993, 73:55-60.

16. Barnard DR, Knue GJ, Dickerson CZ, Bernier UR, Kline DL: Relationship between mosquito (Diptera: Culicidae) landing rates on a human subject and numbers captured using CO2-baited light traps. Bull Entomol Res 2011, 101:277-285.

17. Missawa NA, Ribeiro AL, Maciel GB, Zeilhofer P: Comparison of capture methods for the diagnosis of adult anopheline populations from State of Mato Grosso, Brazil. Rev Soc Bras Med Trop 2011, 44:555-560

18. Mboera LEG, Takken W: Carbon dioxide chemotropism in mosquitoes (Diptera: Culicidae) and its potential in vector surveillance and management programmes. Med Vet Entomol 1997, 85:355-368.

19. Qiu YT, Smallegange RC, Ter BC, Spitzen J, Van Loon JJ, Jawara M, Milligan P, Galimard AM, Van Beek TA, Knols BG, Takken W: Attractiveness of MM-X traps baited with human or synthetic odor to mosquitoes (Diptera: Culicidae) in The Gambia. J Med Entomol 2007, 44:970-983.

20. Okumu FO, Killeen GF, Ogoma S, Biswaro L, Smallegange RC, Mbeyela E, Titus E, Munk C, Ngonyani H, Takken W, Mshinda H, Mukabana WR, Moore $\mathrm{SJ}$ : Development and field evaluation of a synthetic mosquito lure that is more attractive than humans. Plos One 2010, 5:e8951.

21. Kline DL, Takken W, Wood JR, Carlson DA: Field studies on the potential of butanone, carbon-dioxide, honey extract, 1-octen-3-ol, L-lactic acid and phenols as attractants for mosquitos. Med Vet Entomol 1990, 4:383-391.

22. Garrett-Jones C, Magayuka SA: Studies on the Natural Incidence of Plasmodium and Wuchereria infections on Anopheles in Rural East Africa: I Assessment of Densities by Trapping Hungry Female Anopheles gambiae Giles, Species A. Geneva: World Health Organization; 1975.

23. Costantini C, Sagnon NF, Sanogo E, Merzagora L, Coluzzi M: Relationship to human biting collections and influence of light and bednet in CDC light-trap catches of West African malaria vectors. Bull Entomol Res 1998 , 88:503-511.

24. Lines JD, Curtis CF, Wilkes TJ, Njunwa KJ: Monitoring human-biting mosquitoes (Diptera: Culicidae) in Tanzania with light-traps hung beside mosquito nets. Bull Entomol Res 1991, 81:77-84.

25. Davis JR, Hall T, Chee EM, Majala A, Minjas J, Shiff CJ: Comparison of sampling anopheline mosquitos by light-trap and human-bait collections indoors at Bagamoyo, Tanzania. Med Vet Entomol 1995, 9:249-255.

26. Takken W, Knols BGJ: Odor-mediated behavior of Afrotropical malaria mosquitoes. Annu Rev Entomol 1999, 44:131-157.

27. Verhulst NO, Andriessen R, Groenhagen U, Kiss GB, Schulz S, Takken W, van Loon JJA, Schraa G, Smallegange RC: Differential attraction of malaria mosquitoes to volatile blends produced by human skin bacteria. PLoS One 2010, 5:e15829.

28. Logan JG, Birkett MA, Clark SJ, Powers S, Seal NJ, Wadhams LJ, Mordue AJ, Pickett JA: Identification of human-derived volatile chemicals that interfere with attraction of Aedes aegypti mosquitoes. J Chem Ecol 2008, 34:308-322.

29. Jawara M, Smallegange RC, Jeffries D, Nwakanma DC, Awolola TS, Knols BGJ, Takken W, Conway DJ: Optimizing odor-baited trap methods for collecting mosquitoes during the malaria season in The Gambia. PLoS One 2009, 4:e8167.
30. Mboera LEG, Knols BGJ, Braks MAH, Takken W: Comparison of carbon dioxide-baited trapping systems for sampling outdoor mosquito populations in Tanzania. Med Vet Entomol 2000, 14:257-263.

31. Mukabana WR, Mweresa CK, Otieno B, Omusula P, Smallegange RC, van Loon JJA, Takken W: A novel synthetic odorant blend for trapping of malaria and other African mosquito species. J Chem Ecol 2012, 38:235-244

32. Kline DL: Comparison of two American mosquito traps: the professional and a new counterflow geometry trap. J Am Mosa Control Assoc 1999, 15:276-282

33. Krockel U, Rose A, Eiras AE, Geier M: New tools for surveillance of adult yellow fever mosquitoes: comparison of trap catches with human landing rates in an urban environment. J Am Mosq Control Assoc 2006, 22:229-238.

34. Gama RA, da Silva IM, Geier M, Eiras AE: Development of the BG-Malaria trap as an alternative to human-landing catches for the capture of Anopheles darlingi. Mem Inst Oswaldo Cruz 2013, 108:763-771.

35. Okumu FO, Govella NJ, Moore SJ, Chitnis N, Killeen GF: Potential benefits, limitations and target product-profiles of odor-baited mosquito traps for malaria control in Africa. PLoS One 2010, 5:e11573.

36. Verhulst NO, Mukabana WR, Takken W, Smallegange RC: Human skin microbiota and their volatiles as odour baits for the malaria mosquito Anopheles gambiae s.s. Entomol Exp Appl 2011, 139:170-179.

37. Knols BG, Njiru BN, Mathenge EM, Mukabana WR, Beier JC, Killeen GF: MalariaSphere: a greenhouse-enclosed simulation of a natural Anopheles gambiae (Diptera: Culicidae) ecosystem in western Kenya. Malar J 2002, $1: 19$.

38. Menger DJ, Van Loon JJA, Takken W: Assessing the efficacy of candidate mosquito repellents against the background of an attractive source that mimics a human host. Med Vet Entomol doi:10.1111/mve.12061. [Epub ahead of print].

39. Mweresa CK, Omusula P, Otieno B, van Loon JJA, Takken W, Mukabana WR: Molasses as a source of carbon dioxide for the malaria mosquitoes Anopheles gambiae and Anopheles funestus. Malar J 2014, 13:160.

40. Gillies MT, Coetzee M: A Supplement to the Anophelinae of Africa South of the Sahara (Afrotropical Region). Johannesburg: South African Institute for Medical Research; 1987

41. Brady J, Packer MJ, Gibson G: Odor plume shape and host finding by tsetse. Insect Sci App/ 1990, 11:377-384.

42. Cardé RT, Gibson G: Host finding by female mosquitoes: mechanisms of orientation to host odours and other cues. In Olfaction in Vector-Host Interactions, Volume 2. Edited by Takken W, Knols BGJ. Wageningen: Wageningen Academic Publishers; 2010.

43. Mweresa CK: Odour-Based Strategies for Surveillance and Behavioural Disruption of Malaria Mosquitoes and other Mosquito Species. In PhD thesis. Wageningen: Wageningen University; 2014.

44. Matowo NS, Moore J, Mapua S, Madumla EP, Moshi IR, Kaindoa EW, Mwangungulu SP, Kavishe DR, Sumaye RD, Lwetoijera DW, Okumu FO Using a new odour-baited device to explore options for luring and killing outdoor-biting malaria vectors: a report on design and field evaluation of the Mosquito Landing Box. Parasit Vectors 2013, 6:137.

45. Verhulst NO, Qiu YT, Beijleveld H, Maliepaard C, Knights D, Schulz S, Berg-Lyons D, Lauber CL, Verduijn W, Haasnoot GW, Mumm R, Bouwmeester HJ, Claas FH, Dicke M, van Loon JJ, Takken W, Knight R, Smallegange RC: Composition of human skin microbiota affects attractiveness to malaria mosquitoes. PloS One 2011, 6:e28991.

46. Shidrawi GR: Night-bait collection: the variation between persons used as collector-baits. In WHO Technical Notes. Geneva: World Health Organization; 1974:1-18

47. Nyasembe VO, Tchouassi DP, Kirwa HK, Foster WA, Teal PEA, Borgemeister C, Torto B: Development and assessment of plant-based synthetic odor baits for surveillance and control of malaria vectors. PLoS One 2014, 9:e89818.

48. Russell TL, Govella NJ, Azizi S, Drakeley CJ, Kachur SP, Killeen GF: Increased proportions of outdoor feeding among residual malaria vector populations following increased use of insecticide-treated nets in rural Tanzania. Malar J 2011, 10:80

49. Reddy MR, Overgaard HJ, Abaga S, Reddy VP, Caccone A, Kiszewski AE, Slotman MA: Outdoor host seeking behaviour of Anopheles gambiae mosquitoes following initiation of malaria vector control on Bioko Island, Equatorial Guinea. Malar J 2011, 10:184. 
50. Durnez L, Coosemans M: Residual transmission of malaria: an old issue for new approaches. In Anopheles Mosquitoes - New Insights into Malaria Vectors. Edited by Manguin S. Rijeka: InTech; 2013.

51. Smallegange RC, Schmied WH, van Roey KJ, Verhulst NO, Spitzen J, Mukabana WR, Takken W: Sugar-fermenting yeast as an organic source of carbon dioxide to attract the malaria mosquito Anopheles gambiae. Malar J 2010, 9:292.

52. Atieli $H$, Menya D, Githeko A, Scott T: House design modifications reduce indoor resting malaria vector densities in rice irrigation scheme area in western Kenya. Malar J 2009, 8:108.

53. Dugassa S, Medhin G, Balkew M, Seyoum A, Gebre-Michael T: Field investigation on the repellent activity of some aromatic plants by traditional means against Anopheles arabiensis and An. pharoensis (Diptera: Culicidae) around Koka, central Ethiopia. Acta Trop 2009, 112:38-42.

54. Kirby MJ, Ameh D, Bottomley C, Green C, Jawara M, Milligan PJ, Snell PC, Conway DJ, Lindsay SW: Effect of two different house screening interventions on exposure to malaria vectors and on anaemia in children in The Gambia: a randomised controlled trial. Lancet 2009, 374:998-1009

55. Griffin JT, Hollingsworth TD, Okell LC, Churcher TS, White M, Hinsley W, Bousema T, Drakeley CJ, Ferguson NM, Basanez MG, Ghani AC: Reducing Plasmodium falciparum malaria transmission in Africa: a model-based evaluation of intervention strategies. PLoS Med 2010, 7:e1000324.

56. Ferguson HM, Dornhaus A, Beeche A, Borgemeister C, Gottlieb M, Mulla MS, Gimnig JE, Fish D, Killeen GF: Ecology: a prerequisite for malaria elimination and eradication. PLOS Med 2010, 7:e1000303.

57. Govella NJ, Ferguson $\mathrm{H}$ : Why use of interventions targeting outdoor biting mosquitoes will be necessary to achieve malaria elimination. Front Physiol 2012, 3:199.

58. Hiscox A, Maire N, Kiche I, Silkey M, Homan T, Oria P, Mweresa CK, Otieno B, Ayugi M, Bousema T, Sawa P, Alaii J, Smith T, Leeuwis C, Mukabana WR, Takken W: The SolarMal Project: innovative mosquito trapping technology for malaria control. Malar J 2012, 11(Suppl 1):045.

doi:10.1186/1475-2875-13-257

Cite this article as: Hiscox et al.: Development and optimization of the

Suna trap as a tool for mosquito monitoring and control. Malaria Journal 2014 13:257.

\section{Submit your next manuscript to BioMed Central and take full advantage of:}

- Convenient online submission

- Thorough peer review

- No space constraints or color figure charges

- Immediate publication on acceptance

- Inclusion in PubMed, CAS, Scopus and Google Scholar

- Research which is freely available for redistribution 